\title{
The crustal structure of Beira High, Central Mozambique - Combined investigation of wide-angle seismic and potential field data
}

\author{
Christian Olaf Müller ${ }^{1}$, Ingo Heyde ${ }^{2}$, Bernd Schreckenberger ${ }^{2}$, Wilfried Jokat ${ }^{1}$ \\ ${ }^{1}$ Alfred Wegener Institute, Helmholtz Centre for Polar and Marine Research (AWI), Bremerhaven, Germany \\ ${ }^{2}$ Federal Institute for Geosciences and Natural Resources (BGR), Hanover, Germany
}

Up to Jurassic times the Antarctic and African continents were part of the supercontinent Gondwana. Some $185 \mathrm{Ma}$ the onset of rifting caused the dispersal of this vast continent into several minor plates. The timing and geometry of the initial break-up between Africa and Antarctica as well as the amount of volcanism connected to this Jurassic rifting are still controversial. In the southern part of the Mozambique Channel a prominent basement high, the Beira High, forms a distinct crustal anomaly along the Mozambican margin. It is still controversial if this area of shallow basement is a continental fragment or was formed during a period of enhanced magmatism and is of oceanic origin.

Therefore, a wide-angle seismic profile with $37 \mathrm{OBS} / \mathrm{H}$ was acquired starting from the deep Mozambique Channel, across the Beira High and terminating on the shelf off the Zambezi River. The main objectives are to provide constraints on the crustal composition and origin of the Beira High as well as the amount of volcanism and the position of the continent-ocean transition below the Zambezi Delta. To obtain a P-wave velocity model of this area the data were forward modeled by means of the 2D-Raytracing method.

Preliminary results indicate a clear thickening of the crust below the Beira High up to 20-24 $\mathrm{km}$. Evidences for a high velocity body are found in the area below the Zambezi shelf with velocities of 7.2-7.4 km/s and up to $5 \mathrm{~km}$ thickness. Oceanic basement velocities at the very eastern part of the line start with values of $5.5 \mathrm{~km} / \mathrm{s}$, and increase to $6.9 \mathrm{~km} / \mathrm{s}$ at lower crustal levels, that are typical for Jurassic oceanic crust. Across the Beira High the starting velocity and its gradient slightly change, presenting typical values for continental fragments. However, due to a sparse ray coverage of diving waves for the Beira High lower crust, these velocities still have to be proved. Thus, we will introduce the final results of a Finite Difference amplitude modeling, which will constrain the lowermost velocity gradients to allow a sound interpretation of the Beira High origin. The acquired shipborne, magnetic data show a complex magnetic pattern and strong influences by the presence of lava flows and intrusions and require further investigations.

We will introduce the latest results of the joint interpretation of seismic and potential field data sets. 